Volume 1 Nomor 1, Maret 2019, Halaman 54 - 66

\title{
UPAYA MENINGKATKAN KEMAMPUAN BERHITUNG SISWA SD/MI MELALUI PELATIHAN CARA CEPAT DAN TEPAT BERHITUNG DI DESA PRINGGACALA KECAMATAN KARANGAMPEL
}

\author{
Denni Ismunandar, Dian Rohaeni, Feramawati \\ Universitas Wiralodra, denni.ismunandar@unwir.ac.id
}

\begin{abstract}
Abstrak
Pelatihan adalah salah satu unsur dalam menciptakan individu yang lebih berkualitas. Pelatihan sangat diperlukan dalam proses pembelajaran supaya siswa tidak bosan dengan cara belajar yang monoton ketika di dalam kelas. Oleh sebab itu, perlu diadakan sebuah pelatihan kepada siswa mengenai cara cepat dan tepat berhitung untuk mempermudah siswa menghitung operasi penjumlahan dan perkalian. Dengan kegiatan ini diharapkan siswa - siswa dapat lebih mudah memahami materi dalam pelajaran matematika. Selain itu, siswa juga diharapkan termotivasi untuk belajar lebih giat dan tidak bernaggapan bahwa matematika itu sulit. Dari hasil kegiatan, diperoleh masukan bahwa siswa sangat membutuhkan pelatihan cara cepat dan tepat berhitung untuk memudahkan siswa menghitung penjumlahan, pengurangan dan perkalian. Dampaknya adalah hasil belajar siswa dapat lebih baik dan siswa lebih menyukai mata pelajaran matematika Para peserta mengharapkan agar kegiatan pengbadian masyarakat ini dapat dilakukan sesering mungkin dan berkelanjtuan sehingga tetap terjalin komunikasi antar sekolah dan universitas dalam pengembangan pembelajaran.
\end{abstract}

Kata kunci: Cara cepat, berhitung, Operasi hitung.

\begin{abstract}
Training is one element in creating more qualified individuals. Training is very necessary in the learning process so that students are not bored with monotone learning when in class. Therefore, it is necessary to hold a training for students on how to quickly and accurately count to make it easier for students to calculate addition and multiplication operations. With this activity students are expected to be able to more easily understand the material in mathematics. In addition, students are also expected to be motivated to study harder and not think that mathematics is difficult. From the results of the activity, it was obtained input that students desperately need training in a quick and precise way of counting to make it easier for students to calculate addition, subtraction and multiplication. The impact is that student learning outcomes can be better and students prefer mathematics subjects. Participants expect that this community service activity can be carried out as often as possible and continuously so that communication between schools and universities is maintained in the development of learning.

Keywords: How to quickly, count, count operations.
\end{abstract}




\section{PENDAHULUAN}

Matematika merupakan mata pelajaran yang dipelajari mulai dari sekolah dasar menengah hingga perguruan tinggi. Pendidikan matematika di sekolah dasar bertujuan membekali siswa dengan kemampuan berfikir logis, analitis, sistematis, kritis, dan kreatif serta kemampuan bekerja sama. Menurut Suherman (2003) Matematika adalah disiplin ilmu tentang tata cara berfikir danmengolah logika, baik secara kuantitatif maupun secara kualitatif. Sedangkan menurut Abdurahman (2003: 252) matematika adalah bahasa simbolis yang fungsi praktisnya untuk mengekspresikan hubungan-hubungan kuantitatif dan keruangan sehingga fungsi teoritisnya adalah untuk memudahkan berfikir.

Berbicara tentang matematika tidak akan lepas dari berhitung. Berhitung atau aritmatik adalah cabang matematika yang berkenaan dengan sifat hubungan bilangan - bilangan nyata dengan perhitungan terutama berkaitan dengan penjumlahan, pengurangan, perkalian, dan pembagian. Sedangkan kemampuan berhitung cepat adalah daya untuk melakukan komputasi yang berkenaan dengan bilangan-bilangan nyata dan mengaplikasikan konsep yang telah dipahami dalam waktu yang singkat, dengan cara yang mudah, ketelitian dan hasil yang tepat. Berhitung terdapat di seluruh cabang matematika seperti aljabar, geometri, statiska. Berhitung juga diperlukan oleh bidang studi lainnya seperti, fisika, kimia, biologi, bahkan ekonomi. Dalam kehidupan sehari-hari berhitung telah digunakan mulai dari yang sangat sederhana misalnya menghitung pengembalian uang belanja dan lainnya.

Pembelajaran berhitung tidak selamanya berjalan mulus. Apalagi ada anggapan siswa bahwa matematika merupakan salah satu mata pelajaran sulit dan tidak disukai oleh sebagian besar siswa. Bahkan, tidak sedikit siswa yang mengeluh bahwa pelajaran matematika dapat membuat kepala pusing dan stress. Setelah berdiskusi dengan pamong desa dan kepala desa, pelatihan yang biasanya dilakukan adalah pelatohan pembuatan kue, pelatihan tentang pertanian, dan penyuluhan kesehatan, oleh karena itu, akan diadakan pelatihan cara cepat dan tepat berhitung matematika untuk siswa SD/MI di Desa Pringgacala. Dalam pelatihan cara cepat dan tepat berhitung matematika, waktu pengerjaan soal-soalnya menjadi lebih singkat serta yang tadinya dianggap sulit mendadak menjadi mudah. Sehingga dapat menarik minat siswa untuk lebih menyukai matematika dan siswa 
akan menjadi lebih bersemangat. Anggapan-anggapan sulit tentang matematika perlahan akan mulai sirna, kecepatan dan ketepatan siswa ketika berhitung matematika akan membuat siswa lincah dan mahir menyelesaiakan persoalan tentang matematika. Untuk itu, diperlukan pelatihan dan pembelajaran yang tepat supaya siswa mendaapatkan hasil belajar yang baik.

Pembelajaran adalah proses interaksi peserta didik dengan pendidik dan sumber belajar pada suatulingkungan belajar. Peserta didik yang dimaksud adalah siswa dan pendidik adalah guru. Menurut Syaiful Bahri Djamarah, (2002: 43) Pengertian Pembelajaran adalah suatu kondisi yang dengan sengaja diciptakan oleh guru guna membelajarkan siswa. Adapun menurut Erman Suherman (2003: 8) mengartikan pembelajaran sebagai upaya penataan lingkungan yang memberi nuansa agar program belajar tumbuh dan berkembang secara optimal. Sedangkan menurut Sugihartono (2007: 81), pembelajaran adalah suatu upaya yang dilakukan oleh guru untuk menyampaikan ilmu pengetahuan, mengorganisir, dan menciptakan sistem lingkungan dengan berbagai metode sehingga siswa dapat melakukan kegiatan belajar secara efektif dan efisien serta dengan hasil yang optimal.

Matematika diartikan oleh Johnson dan Rising (Erman Suherman, 2003: 19) sebagai pola berpikir, pola mengorganisasi, pembuktian yang logik, bahasa yang menggunakan istilah yang didefinisikan dengan cermat, jelas, dan akurat representasinya dengan simbol dan padat. Matematika menurut Erman Suherman (2003:253) adalah disiplin ilmu tentang tata cara berfikir dan mengolah logika, baik secara kuantitatif maupun secara kualitatif. Sejarah menunjukkan bahwa matematika sangat dibutuhkan manusia. Dapatkah kita membayangkan bagaimana dunia ini sekarang seandainya matematika tidak ada. Bagaimana kacaunya dunia ini seandainya orang tidak dapat berhitung. Oleh karena itu, konsep-konsep matematika (termasuk di dalamnya berhitung) yang dipelajari di SD/MI merupakan konsep-konsep dasar yang sangat diperlukan agar siswa dapat mengerjakan pekerjaan menghitung. Penguasaan konsep-konsep dasar matematika di SD/MI sangat berguna untuk dapat memahami matematika dan ilmu-ilmu lain yang semakin kompleks yang akan dipelajari di jenjang yang lebih tinggi. 
Berhitung merupakan suatu hal yang berkaitan dengan perhitungan terutama menyangkut penjumlahan, pengurangan, perkalian dan pembagian. Berhitung bukan hanya menyuarakan bahasa tulis atau menirukan ucapan guru dengan cepat, akan tetapi berhitung merupakan perbuatan yang dilakukan berdasarkan kerjasama beberapa keterampilan individu dalam mengamati, menyebutkan, memahami dan menulis lambing bilangan yang pasti dan sesuai dengan informasi. Menurut Wahyudi dan Damayanti (2005: 104) matematika (berhitung) meliputi semua pemikiran dan keahlian yang membantu manusia dalam mengatur dunia. Pemikiran dan keahlian untuk anak-anak meliputi mencocokkan, mengelompokkan, mengatur, berhitung, memisahkan, mengukur, dan membandingkan. Anak juga akan belajar melalui pengalamannya dengan bentuk, ukuran, ruang, angka, dan simbol-simbol angka.Dengan demikian, dari penjelasan di atas dapat disimpulkan bahwa pembelajaran matematika adalah proses interaksi antara guru dan siswa yang melibatkan pengembangan pola berfikir dan mengolah logika pada suatu lingkungan belajar yang sengaja diciptakan oleh guru dengan berbagai metode agar program belajar matematika tumbuh dan berkembang secara optimal dan siswa dapat melakukan kegiatan belajar secara efektif dan efisien.

Berdasarkan analisis situasi, tinjauan pustaka dan pengalaman di lapangan dapat diidentifikasi masalah bahwa (1) Berhitung cepat dan tepat matematika masih rendah, (2) keaktifan siswa dalam mengikuti mata pelajaran matematika masih belum nampak. (3) belum ada pelatihan berhitung cepat dan tepat dalam berhitung matematika. Manfaat setelah diadakan kegiatan ini diharapkan dapat mengoptimalkan cara cepat dan tepat berhitung matematika. Tujuan dari pengabdiaan ini adalah siswa mampu mengoptimalkan kemampuannya dalam berhitung dengan cepat pada mata pelajaran matematika dan siswa dan lebih menyukai pelajaran matematika sehingga berdampak pada peningkatan hasil belajar siswa.

\section{METODE}


Pengabdian masyarakat ini dilakukan di desa Pringgacala kecamatan Karang Ampel Kabupaten Indramayu. Kegiatan ini dilaksanakan selama tiga bulan untuk melatih mahasiswa mengimplementasikan ilmu yang telah didapatkan selama beberapa semester di bangku kuliah ke masyarakat. Kegiatan pelatihan cara cepat dan tepat berhitung dilaksanakan setiap pulang sekolah selama 1 jam pada tingkatan SD yang berada di Desa pringgacala. Metode dalam pengabdian masyarakat ini adalah dengan menggunakan metode pendidikan masyarakat. Target pengabdian ini adalah siswa SD/MI di wilayah desa Pringgacala kacamatan Karangampel. Teknik pengumpulan data dilakukan dengan memberikan angket kepada siswa yang mengikuti kegiatan. Analisis data menggunakan bantuan software exell untuk mengetahui tingkat kepuasan peserta pelatihan. Pelaksanaan kegiatan pengabdian ini mengikuti aktivitas pelaksanaan penelitian tindakan yang terdiri dari Persiapan/Perencanaan, Pelaksanaan, Evaluasi dan Refleksi.

Penjelasan setiap tahap pelaksanaan pengabdian masyarakat adalah sebagai berikut. (1) Perencanaan awal pengabdian adalah sebagai berikut. a) Melakukan kordinasi dengan Lembaga Pemberdayaan Masyarakat Universitas Wiralodra Indramayu dan Dinas Pendidikan dan Kebudayaan Kabupaten Indramayu dilanjutkan ke UPTD Kecamatan Karangampel. b) Sosialisasi kegiatan pengabdian SD/MI di Desa Pringgacala Kecamatan Karangampel.(2) Pelaksanaan, dilakukan dengan dua metode, yaitu ceramah dan praktik. (a) Metode ceramah untuk memberi penjelasan tentang cara cepat dan tepat berhitung matematika. (b) Metode praktik untuk pelatihan cara cepat dan tepat berhitung matematika. (c) Metode diskusi untuk membahas tentang cara cepat dan tepat berhitung matematika. (3) Kegiatan evaluasi dilakukan secara langsung oleh pelaksana. Evaluasi berupa hasil kerja peserta terhadap pelatihan cara cepat dan tepat berhitung matematika. Proses evaluasi dilaksanakan untuk mengetahui kekurangan dan kendala dalam pelaksanaan kegiatan. (4) Refleksi dilakukan bersama antara pelaksana dan siswa. Hal ini dilakukan untuk mengetahui seluruh proses pelaksanaan kegiatan.

\section{PEMBAHASAN}


Berikut beberapa trik cepat dan tepat berhitung matematika yang mudah dan menyenangkan.

1. Pengkuadratkan dua angka yang bilangannya diakhiri angka satu

Langkah yang digunakan

a. Kuadratkan angka bulatnya

b. Jumlahkan angka yang dikuadratkan dengan angka bulatnya

c. Hasil adalah jumlah dari "a $+b$ "

Contoh

1. Temukan hasil dari $51^{2}$ ?

Langkah :

a. $50^{2}=2500$

b. $51+50=101$

c. Hasil $2500+101=2601$

2. Pengkuadratan dua angka yang bilangannya dimulai dengan lima Langkah yang digunakan

a. Tambah angka 25 dan tambah dengan bilangan satuan angka yang dikuadratkan

b. Kuadratkan nilai satuannya (untuk angka 1,2,3 ditulis dengan 01,04,09)

c. Hasil adalah nilai "a" digabungkan dengan nilai "b"

Contoh

1. Temukan hasil dari $52^{2}$ ?

Langkah :

a. $25+2=27$

b. $2^{2}=4$ ditulis 04

d. Hasilnya adalah 2704

3. Pengkuadratan dua angka yang berakhiran dengan angka lima

Langkah yang digunakan

a. Kalikan angka puluhan pada bilangan yang dikuadratkan dengan angka urutan

b. Tambahkan angka 25 dibelakang hasil nilai "a"

Contoh 
1. Temukan hasil dari $35^{2}$ ?

Langkah :

a. Angka puluhannya 3 maka $3 \times 4=12$

b. Hasilnya adalah 1225

4. Perkalian dua angka dengan 11

Langkah yang digunakan

a. Tuliskan angka yang dikalian

b. Jumlahkan angka perkalian

c. Hasil dari "b" disisipkan pada angka yang dikalikan (untuk hasil yang lebih dari 9, angka puluhannya dijumlahkan dengan hasil angka pertama) Contoh

1. Temukan hasil dari $44 \times 11$ ?

Langkah :
a. $\quad 4 \rightarrow 4=4 ? 4$
b. $4+4=8$
c. Hasilnya adalah 484

2. Tentukan hasil dari $48 \times 11$ ?

Langkah

a. $4 \rightarrow 8=4$ ? 8

b. $4+8=12$

d. Karena hasil "b" merupakan dua angka maka angka hasil ditambahkan dengan angka pertama perkalian $4+1=5$. Hasilnya adalah 528

5. Perkalian satu atau dua angka dengan 99

Langkah yang digunakan

a. Kurangi bilangan yang akan dikalikan dengan angka 1

b. Kurangi yang akan dikalikan dengan 100

c. Hasil adalah gabungan dari hasil nilai "a" dan "b"

Contoh

1. Temukan hasil dari $8 \times 99$ ?

Langkah : 

a. $8-1=7$
b. $100-8=92$
c. Hasilnya adalah 792

2. Temukan hasil dari $55 \times 99$ ?

Langkah :
a. $55-1=54$
b. $100-55=45$
c. Hasilnya adalah 5445

6. Perkalian bilangan genap dengan “...,5” $(1,5 ; 2,5 ; 3,5 ; 4,5 \ldots$ dan seterusnya) Langkah yang digunakan
a. Kalikan bilangan pengali dengan 2
b. Bilangan yang dikalikan dibagi 2
c. Hasil adalah perkalian antara hasil nilai "a" dan "b"

Contoh

1. Temukan hasil dari $42 \times 3,5$ ?

Langkah :
a. $3,5 \times 2=7$
b. $42 \div 2=21$
c. Hasilnya adalah $7 \times 21=147$

7. Perkalian satu atau dua angka dengan 101 Langkah yang digunakan :
a. Tuliskan angka bilangan yang dikalikan sebanyak 2 kali
b. Untuk perkalian satu angka sisipkan 0

Contoh

1. Temukan hasil dari $9 \times 101$ ?

Langkah :
a. 99
b. Karena perkaliannya satu angka maka disisipkan 0 , Hasilnya adalah 909

2. Temukan hasil dari $75 \times 101$ ?

Langkah : 
a. 7575

b. Hasilnya adalah 7575

8. Perkalian antara dua bilangan yang nilainya berselisih dua

Langkah yang digunakan :

a. Kuadratkan nilai diantaranya

b. Hasil adalah nilai "a" dikurangi 1

Contoh

1. Temukan hasil dari $14 \times 16$ ?

Langkah :

a. $14 \times 16 \rightarrow 15=15^{2}=225$

b. $225-1=224$

9. Perkalian dua bilangan yang bernilai puluhan sama dan bilangan satuan harus bernilai sepuluh (10)

Langkah yang digunakan :

a. Kalikan bilangan angka yang dikalikan dengan bilangan berikutnya (missal jika 1 maka dikali 2 )

b. Kalikan masing-masing bilangan satuannya

c. Hasil adalah gabungan dari hasil nilai "a" dan nilai "b"

Contoh

1. Temukan hasil dari $15 \times 15$ ?

Langkah :
a. $1 \times 2=2$
b. $5 \times 5=25$
c. Hasilnya adalah 225

2. Temukan hasil dari $28 \times 22$ ?

Langkah :
a. $2 \times 3=6$
b. $8 \times 2=16$. Hasilnya adalah 616

Kegiatan pengabdian pada masyarakat ini berupa bimbingan belajar tentang cara cepat dan tepat berhitung matematika yang dilaksanakan pada hari senin-rabu 
tanggal 21 - 23 Juli 2017 dengan mengambil tempat di posko KKN Desa Pringgacala yang diikuti oleh 20 orang peserta.

Pelatihan cara cepat dan tepat pembelajaran matematika berfungsi untuk meningkatkan minat siswa untuk lebih menyukai pelajaran matematika dan siswa menjadi lebih bersemangat serta meningkatkan kecepatan berhitung dan pemahaman tentang matematika. Hasil dari kegiatan pengabdian masyarakat yang dilakukan pada tingkat SD/MI di desa pringgacala berdasarkan angket terbuka antara lain: (a) Kegiatan ini menambah pengetahuan siswa tentang cara cepat dan tepat berhitung matematika pada mata pelajaran matematika yang dapat menarik dan meningkatkan kualitas siswa SD/MI; (b) Kegiatan ini menambah pengetahuan siswa tentang perkembangan cara perhitungan matematika yang semakin modern; (c) siswa merasa bahwa matematika itu menyenangkan. Dalam pelaksanaan kegiatan pengabdian masyarakat ini tidak terlepas dari faktorfaktor pendukung dan penghambat. Faktor pendukung dalam keterlaksanaan kegiatan. ini adalah semangat peserta yang sangat tinggi dalam mengikuti pelatihan cara cepat dan tepat berhitung matematika dan juga semangat pengabdian para pelatih dalam memberikan materi pelatihan.

Terlepas dari beberapa faktor pendukung diatas, terdapat beberapa faktor penghambat yang dapat dijadikan evaluasi untuk pelaksanaan kegiatan pengabdian masyarakat di periode yang akan datang yaitu kondisi ruang dan waktu pelaksanaan pelatihan yang sangat terbatas. Kendala ini dapat diatasi dengan penggunanaan alokasi waktu yang efisien dan efektif dengan melakukan melakukan pemilihan dan penyusunan materi yang tepat untuk diberikan pada pelatihan cara cepat dan tepat berhitung matematika. Faktor penghambat lain adalah tidak adanya monitoring dan angket pelaksanaan kegiatan. Berikut foto kegiatan pelaksanaan pelatihan berhitung cepat dan tepat di SD Desa Pringgacala kecamatan Karang Ampel. 

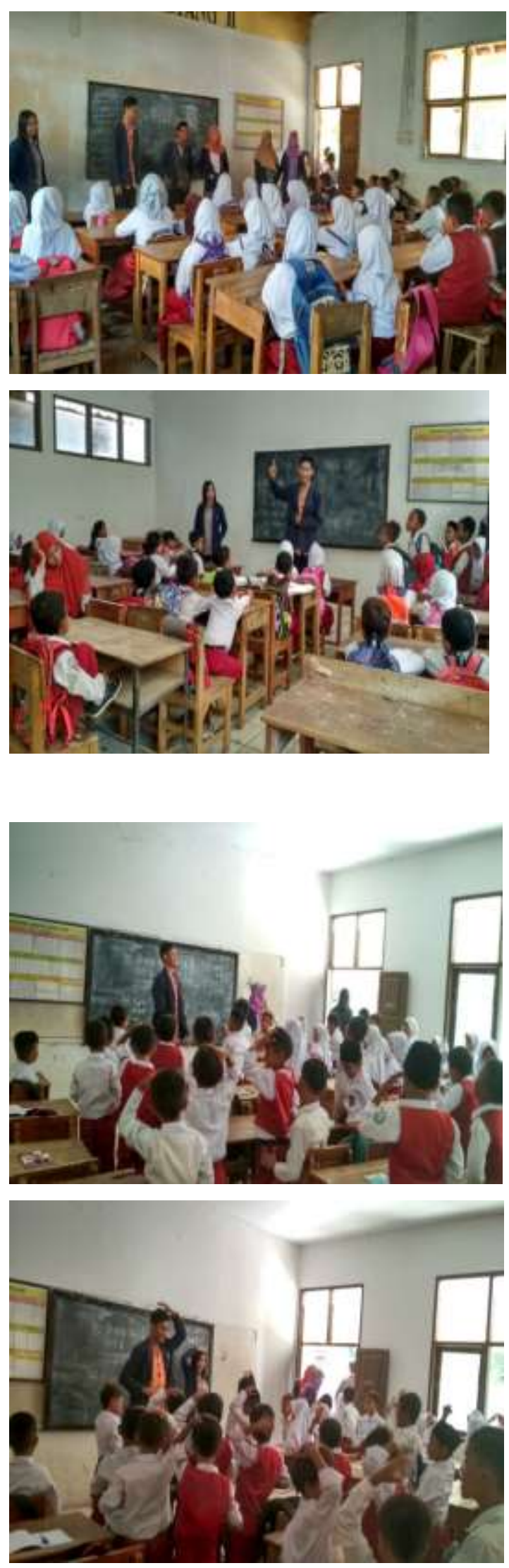


\section{SIMPULAN DAN SARAN}

\section{SIMPULAN}

1) Kegiatan pelatihan cara cepat dan tepat berhitung matematika ini sangat membantu peserta dalam mengembangkan program-program pembelajaran matematika dan menambah wawasan siswa.

2) Meningkatkan minat siswa untuk lebih mendalami matematika dan siswa menjadi lebih bersemangat .

3) Anggapan-anggapan sulit tentang matematika perlahan akan mulai sirna, kecepatan dan ketepatan siswa ketika berhitung matematika akan membuat siswa lincah dan mahir menyelesaiakan persoalan tentang matematika.

4) Mengingat banyaknya manfaat yang dapat oleh siswa dari kegiatan ini, pelatihan dapat dilakukan sebanyak mungkin dan berkelanjutan dengan disertai pengembangkan dari materi pelatihan itu sendiri.

5) Kegiatan ini menambah pengetahuan siswa tentang cara cepat dan tepat berhitung matematika pada mata pelajaran matematika yang dapat menarik dan meningkatkan kualitas siswa SD/MI.

6) Kegiatan ini menambah pengetahuan siswa tentang perkembangan cara perhitungan matematika yang semakin modern.

7) Siswa merasa bahwa matematika itu menyenangkan.

\section{SARAN}

1) Tim pengabdian selanjutnya dapat lebih menganalisis mengenai peningkatan hasil belajar siswa setelah menndapatkan pelatihan berhitung cepat dan tepat.

2) Perlu adanya pendampingan dan kerjasama dari pihak desa, karena dalam pemberdayaan masyarakat dibutuhkan juga pendampingan dari sekolah dan pihak desa.

\section{DAFTAR PUSTAKA}

Abdurahman Mulyono. 2003. Pendidikan bagi Anak Berkesulitan Belajar. Jakarta: Rineka Cipta.

Sugihartono. 2007. Psikologi Pendidikan. Yogyakarta. UNY Press. 
Suherman, Erman. 2013. Strategi Pembelajaran Matematika. Bandung: JICA UPI. Syaiful Bahri Djamarah. 2002. Psikologi Belajar. Jakarta: PT. Rineka Cipta Wahyudi. 2005. Program Pendidikan untuk anak Usia Dini di Prasekolah Islam. Jakarta: Grasindo. 